\title{
La Educación Superior Inclusiva en Algunos Países de Latinoamérica: Avances, Obstáculos y Retos
}

\author{
Inclusive Higher Education in Some Latin American Countries: \\ Progress, Obstacles and Challenges
}

\author{
M. Stella Fajardo * \\ Universidad de Manizales-Cinde
}

\begin{abstract}
El presente artículo analiza los trabajos que dan cuenta del saber acumulado en investigaciones y estudios empíricos de los últimos diez años en algunos países de Latinoamérica y Colombia considerados relevantes en relación con la implementación de las políticas de educación inclusiva en el nivel superior. La base del análisis es de carácter documental, se consultaron artículos, tesis de grado e informes, que permitieron evidenciar la evolución de las Universidades en el tránsito del sistema educativo hacia una educación inclusiva para las personas con discapacidad. Se muestran múltiples y diversas realidades, en algunos casos contradictorias entre el reconocimiento de la garantía del derecho a la educación inclusiva evidente en las políticas públicas y las prácticas reales de inclusión, que son propias de una universidad que desde hace poco tiempo procura ofrecer respuestas a la atención de la diversidad.
\end{abstract}

Descriptores: Derecho a la educación, Política Educacional, Práctica pedagógica, Universidad, Diversidad cultural.

\begin{abstract}
This article analyzes the work that realize the accumulated knowledge in research and empirical studies of the last ten years in some countries of Latin-América and Colombia, considered relevant in relation with implementation of inclusive education policies in the highest level. The basis of the analysis is the documental recompilation articles, theses and reports, were examined, they let to show the Lain American Universities evolution in the transition of the educative system towards an inclusive education for people with disabilities. Multiple and diverse realities are shown, in some cases contradictory between recognition of the right to inclusive education's guaranties evident in the public policies, and the real practices of inclusion, that are typical of an university that since not a long time ago tries to offer answers to the assistance of the diversity.
\end{abstract}

Keywords: Right to education, Educational policy, Pedagogical practice, University, Cultural diversity.

\footnotetext{
Artículo temático de reflexión derivado de la investigación titulada "La inclusión educativa de los jóvenes con discapacidad en la Educación Superior: voces y experiencias de reconocimiento desde el enfoque de la diversidad y la perspectiva de derechos", desarrollada en la línea de investigación Educación y Pedagogía del Doctorado en Ciencias Sociales, Niñez y Juventud de la Universidad de Manizales-CINDE. Doctorado en curso. Área: Ciencias Sociales. Subárea: Ciencias de la Educación.
}

$\begin{array}{lll}\text { *Contacto: mystelafabe9699@gmail.com } & \text { Recibido: } & 7 / 11 / 2016 \\ & 1^{\text {a Evaluación: }} 15 / 01 / 2017 \\ \text { ISSN: 0718-7378 } & \text { Aceptado: } & 18 / 03 / 2017 \\ \text { www.rinace.net/rlei/ } & \end{array}$




\section{Introducción}

La Educación Inclusiva se ha convertido en un tema de interés y de debate a nivel internacional y nacional; especialmente en el marco de las políticas públicas en educación se observa la necesidad de adaptar la educación superior a grupos tradicionalmente excluidos de ella: personas en situación de pobreza, indígenas, desplazados, personas con discapacidad ( $\mathrm{PcD})$, etc. Igualmente, la inclusión educativa de las personas con discapacidad ha alcanzado consenso internacional a partir de la promulgación por la Organización de Naciones Unidas-ONU, de la Convención sobre los Derechos de las Personas con Discapacidad emitida en 2006. En este contexto, el presente artículo tiene como propósito ubicar el campo temático de la inclusión educativa en las Instituciones de Educación Superior (IES), en un marco de referencia internacional y nacional que muestre en una línea de tiempo, el estado de la cuestión desde el punto de vista de la implementación de las políticas públicas educativas, las normativas y lineamientos internacionales, nacionales, sectoriales en educación y las políticas de las Instituciones de Educación Superior que han posibilitado la creación de observatorios, comisiones, organismos, redes instituciones e interinstitucionales, comités, programas y modelos de atención a las personas con discapacidad en diversos países Iberoamericanos. Se analizan antecedentes que muestran los esfuerzos adelantados en los últimos años para la creación y puesta en marcha de instancias y estamentos que se interesan por ofrecer los lineamientos para una formación de calidad para las personas con discapacidad en las Instituciones de Educación Superior. Se efectúa un análisis de las iniciativas, orientaciones, acciones adelantadas, avances y potencialidades; se analizan las problemáticas que se derivan de ella, obstáculos, limitaciones y tensiones que se evidencian en los procesos adelantados en pro de una Educación superior inclusiva en la región y que marcan un derrotero para proponer recomendaciones e identificar prospectivamente los desafíos y retos de la Educación superior inclusiva. El análisis permite finalmente identificar algunos vacíos teóricos y prácticos, que dan lugar a la puesta en marcha de nuevas investigaciones en este campo de estudio.

\section{Implementación de políticas sobre educación superior inclusiva en Iberoamérica y Colombia}

\subsection{Lineamientos, políticas públicas y normativas}

Un primer eje de abordaje tiene relación con los Lineamientos internacionales, las políticas públicas y normativas nacionales y sectoriales en educación que sustentan la puesta en marcha de la educación superior inclusiva.

Desde los lineamientos Internacionales es necesario resaltar en primer lugar, la Convención sobre los Derechos de las Personas con Discapacidad (ONU, 2008), donde se señala que los valores que promueve el paradigma de la inclusión se basan en el reconocimiento de las personas con discapacidad como sujetos de derecho. Todas las personas con discapacidad, como sujetos políticos, tienen derecho no sólo a manifestar sus necesidades y deseos, sino también a participar con sus opiniones en la toma de decisiones sobre todos aquellos aspectos que los afectan o inciden sobre su vida personal y el ejercicio de su ciudadanía. Tres principios sustentan el enfoque de educación basado 
en los derechos: a) acceso a una educación obligatoria y gratuita; b) el derecho a una educación de calidad; c) igualdad, inclusión y no discriminación.

Un Segundo Lineamiento Internacional relevante es el Informe Mundial sobre la Discapacidad (Organización Mundial de la Salud, 2011), que propone

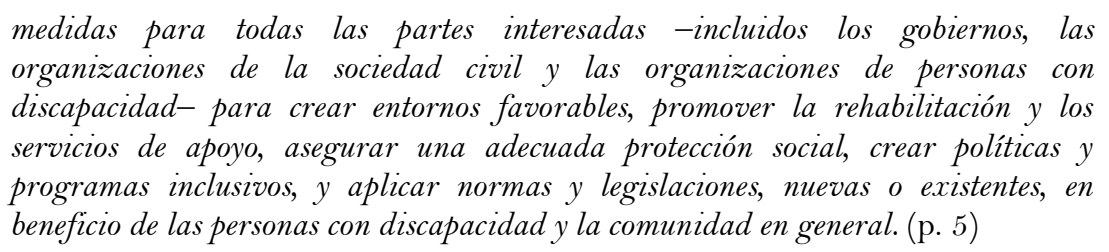

El modelo social de la discapacidad es sostenido por la Organización Mundial de la Salud en el marco de las Convenciones y Principios de los Derechos Humanos.

En este marco contextual, es necesario reconocer los esfuerzos que en el ámbito de las políticas públicas y normativas del orden Nacional y Sectorial (Ministerios de Educación) se han adelantado en algunos países Iberoamericanos. La Asociación Nacional de Universidades e Instituciones de Educación Superior- (ANUIES) y la Secretaría de Educación Pública de México (SEP) (2004) muestran que en México, es a partir de 1995 que se da inicio al "Programa Nacional para el Bienestar y la incorporación al desarrollo de las personas con discapacidad" que acoge los postulados de la Secretaría de Salud, el Programa Nacional para el Bienestar y la Incorporación al Desarrollo de las Personas con Discapacidad de la Presidencia de la República, y del Sistema Nacional de Desarrollo Integral para la Familia y la Secretaría de Educación pública de México. Posteriormente, el 30 de Mayo de 2011 se expide la Ley General para la Inclusión de las Personas con Discapacidad, cuyo objeto es reglamentar lo conducente al Artículo 1o. de la Constitución Política de los Estados Unidos Mexicanos, estableciendo las condiciones en las que el Estado deberá promover, proteger y asegurar el pleno ejercicio de los derechos humanos y libertades fundamentales de las personas con discapacidad, asegurando su plena inclusión a la sociedad en un marco de respeto, igualdad y equiparación de oportunidades.

Rodríguez (2004) afirma que en Ecuador la integración de las personas con discapacidad a la educación superior, oscila alrededor del $1.8 \%$ del total de la población. Señala el marco legal -el 10 de agosto de 1992 se publica Ley sobre discapacidades- que determina las obligaciones de las instituciones y organismos para propiciar la inclusión educativa y social. Posteriormente, en la nueva redacción de la constitución del país aprobada en el año 2008, queda reflejado en su sección sexta dedicada a personas con discapacidad, artículo 47 que señala “(...) el Estado garantizará políticas de prevención de las discapacidades y, de manera conjunta con la sociedad y la familia, procurará la equiparación de oportunidades para las personas con discapacidad y su integración social" (Constitución de la República del Ecuador, 2008). Recientemente, el Ministerio de Educación de Ecuador mediante el Acuerdo No. 0295-13 del 15 de agosto de 2013, expide la normativa referente a la atención de estudiantes con necesidades educativas especiales en establecimientos de educación ordinaria o en instituciones educativas especializadas.

El Observatorio Latinoamericano de Políticas Educativas, apoyado por la Fundación Ford con el auspicio de la Secretaría Especial de Promoción de Políticas de Igualdad Racial del Gobierno Federal de Brasil (Sverdilick, Ferrari y Jaimovich, 2005) adelanta un estudio comparado con relación a las políticas de acción afirmativa en la educación 
superior, que redundan en un mayor acceso y/o retención de sectores tradicionalmente excluidos o relegados. El estudio concluye que es posible distinguir dos grandes grupos de políticas: dentro del primer grupo, las políticas mayoritarias están representadas, por ejemplo, en becas de ayuda económica, las cuales combinan como requisitos de otorgamiento un buen rendimiento académico sumado a la necesidad económica; este tipo de políticas es común en países como Chile o Argentina. El segundo grupo de políticas centradas en la atención a la diversidad, se evidencia en países como Brasil, Colombia o México.

El documento base de la conferencia Regional de Educación Superior, producto del proyecto "Tendencias de la educación superior en América Latina y el Caribe", fue presentado por la IESALC-UNESCO bajo la dirección de Aponte (2008). El texto discute tanto la desigualdad como los movimientos en dirección hacia la inclusión y la equidad en la educación superior y hace recomendaciones en cuanto a políticas públicas e institucionales. Se destaca que las políticas de inclusión de los países de la región para promover la participación de los grupos excluidos o sectores que experimentan dificultad para ingresar, progresar y terminar los estudios superiores se concentran en un grupo de países que tiene disposiciones constitucionales para integrar o incluir a estos sectores de la población a la educación superior. Veinte países de la región han consagrado garantías de participación e inclusión de personas con discapacidad en sus marcos legales y políticas de acceso a las instituciones, aunque las políticas y prácticas institucionales excluyen los derechos, la asignación de recursos, y programas de apoyo y servicios a profesores, estudiantes y personal de apoyo para esta gestión institucional.

Pedroza y Villalobos (2009) abordan el estudio de las políticas compensatorias o de acción afirmativa que se aplican en la educación superior en Ecuador y Perú. En Perú, el mandato de la Ley de Educación reconoce que la Educación Especial tiene un enfoque inclusivo, atiende a personas con necesidades educativas especiales (discapacidades y talentos) con el fin de conseguir su integración en la vida comunitaria y su participación en la sociedad; este tipo de educación se debe impartir en aulas regulares con miras a su inclusión, sin desconocer la atención especializada que requieren. Acorde con la Ley 27050 (Ley general de las Personas con Discapacidad), se establece el derecho a ser admitidos en colegios regulares; se instaura el uso de sistemas especiales de pruebas en Braille para ciegos y en lenguaje de señas para sordos; la adecuación de infraestructura física de centros educativos (accesibilidad); la necesidad de implementar adecuaciones curriculares. Se otorga un $15 \%$ adicional en puntajes de concursos para empleos públicos a las personas con discapacidad, y un $5 \%$ de cuotas en el ingreso a Universidades Públicas. Se resalta que pese a los esfuerzos desarrollados en materia de políticas compensatorias para la equidad en Ecuador y Perú, aún se concentra la mayor dificultad entre los que menos tienen, es decir, en los jóvenes en pobreza o en extrema pobreza, la población indígena, la población femenina y la población con discapacidad o capacidades diferentes, lo cual limita la participación de todos estos grupos vulnerables en la educación superior.

En Colombia, Flórez y colaboradores (2009), a partir de una revisión de la política y los lineamientos de inclusión de personas con discapacidad, presentan una propuesta de lineamientos de política para la atención educativa de poblaciones en situación de discapacidad en las instituciones de educación superior en Colombia. Esta propuesta se construyó en el marco del Observatorio de Discapacidad de la Maestría en Discapacidad e Inclusión Social de la Universidad Nacional de Colombia. Para su realización se contó 
con el apoyo de la Vicepresidencia de la República, Programa de Discapacidad y Derechos Humanos y del Ministerio de Educación Nacional, Subdirección de Poblaciones. Se presentan los antecedentes a nivel legislativo y de política pública, un marco conceptual sobre educación inclusiva, principios orientadores referidos a la igualdad de oportunidades y flexibilidad curricular; igualmente muestra el contexto de construcción de los lineamientos, las líneas de intervención propuestas a las instituciones de educación superior para generar planes, programas y proyectos para avanzar hacia Educación superior inclusiva, enfocadas a cinco áreas de intervención: formación y capacitación, construcción de tejido social, eliminación de barreras, adaptaciones tecnológicas y adaptaciones curriculares. Finalmente, se establecen condiciones y acciones para la intervención y la aplicación referidas a la generación de políticas institucionales que propicien la inclusión, con la participación en redes interinstitucionales y garantías para el acceso, tránsito y permanencia de la población en situación de discapacidad en el nivel superior, la calidad de los servicios educativos y la adaptación de las condiciones propias del proceso educativo. La propuesta identifica las fases o etapas que conformarían los procesos académicos y se definen las acciones, los compromisos y actores involucrados para garantizar la calidad de los servicios educativos para los estudiantes en condición de discapacidad, tanto en las instancias gubernamentales como en las IES. Se resalta la importancia de este antecedente como documento base para la consolidación en 2013 de los "Lineamientos de la política de Educación superior inclusiva" en Colombia.

Este artículo fue uno de los documentos base sobre los cuales se desarrollaron las mesas de trabajo para la construcción de los Lineamientos para una política en Educación superior inclusiva elaborado por la Subdirección de apoyo a la Gestión de las IES del Ministerio de Educación Nacional. (Flórez et al., 2009, p. 11)

Moreno (2010) en su tesis doctoral "Políticas para la población infantil con discapacidad efectúa un análisis de la normatividad colombiana desde la perspectiva de justicia”, se analizó la normatividad colombiana generada entre 1993 y 2005, a partir de un análisis con enfoque sistémico, que responde la pregunta sobre la capacidad que tiene la normatividad colombiana para asegurar una vida digna para la población infantil colombiana con discapacidad. Las normas fueron exploradas mediante un análisis documental, con una adaptación del dispositivo analítico derivado por Turnbull y Stowe (2001) retomado por Moreno (2010), de la valoración de la política norteamericana en el área de la discapacidad. Este dispositivo articula, en el nivel primario, 18 conceptos nucleares que fundamentan la política en discapacidad, los cuales se organizan en nueve principios, a la vez, agrupados en tres categorías mayores reconocidas como principios constitucionales, éticos y administrativos. Este sistema es considerado por la autora como una teoría sobre política en discapacidad.

Los resultados del estudio exploratorio revelaron que el contenido de la normatividad colombiana, por un lado: 1) privilegia tres conceptos nucleares: la antidiscriminación, la integración de la persona con discapacidad a la vida en sociedad y la prevención de la discapacidad; mientras que, por otro, 2) restringe conceptos como los de clasificación y coordinación y colaboración en los servicios, capacidad instalada del sistema y de los profesionales, servicios individualizados y apropiados, empoderamiento, y participación frente a la toma de decisiones, 3) distorsiona conceptos como la autonomía, la libertad, los servicios basados en capacidades, los servicios centrados en la atención a las familias, y la rendición de cuentas; y 4) excluye principios como los de protección del daño, 
privacidad y confidencialidad, productividad y contribución, integridad y unidad familiar, y sensibilidad cultural.

Crosso (2010) en un estudio comparado toma como base para su análisis el Informe "Derecho a la educación de las personas con discapacidad en América Latina y el Caribe", elaborado por la Campaña Latinoamericana por el Derecho a la Educación y presentado en alianza con el Centro por la Justicia y el Derecho Internacional y el Relator Especial de las Naciones Unidas para el Derecho a la Educación a la Comisión Interamericana de Derechos Humanos en el 2009. Señala que un reto para los Estados de América Latina y el Caribe es el de armonizar la legislación nacional con los enunciados de la Convención sobre los Derechos de las Personas con Discapacidad y los marcos legales y normativos internacionales; en este proceso los estados deben considerar que las repercusiones de los marcos legislativos nacionales dependerán del grado de aplicación, de la continuidad de la financiación, de una verdadera supervisión y evaluación, así como de marcos normativos más pormenorizados que garanticen que las normas jurídicas se reflejen en la práctica y en los programas. Los estados deben determinar normas en materia de educación para velar porque las personas con discapacidad puedan disfrutar de una educación disponible, accesible, aceptable y adaptable en igualdad de condiciones que el resto de los ciudadanos y ciudadanas; estas normas deben contemplar la promoción de la formulación de planes de estudio comunes a todos los/as estudiantes y la promoción de la educación y el aprendizaje de los derechos humanos; la coordinación de todas las esferas de reforma educativa para velar por la coherencia con el derecho a la educación y la educación inclusiva.

Giraldo (2013) en su trabajo de Grado de la Maestría en Derecho de Universidad Nacional de Colombia, propone una sistematización jurisprudencial de los fallos de la Corte Constitucional Colombiana (1992-2011) frente al de la educación inclusiva. Apeló a la herramienta de la sistematización jurisprudencial de los fallos de la Corte Constitucional durante el periodo comprendido entre el año de 1992 a 2011 teniendo en cuenta los criterios de educación especial, educación integrada y educación inclusiva. Aunque la Convención de los Derechos Humanos de las Personas con Discapacidad sólo fue ratificada por el Congreso Colombiano en el año 2009, se incluyeron los pronunciamientos que emitió esta Corporación desde sus inicios para evidenciar los avances y retrocesos acerca de la realización efectiva del derecho a la educación para todos y todas. La sistematización jurisprudencial sobre el derecho a la educación en sus diferentes visiones: especial, integrada e inclusiva, tomó como criterio para seleccionar las sentencias, la identificación de patrones fácticos, cuyo descriptor general fue "educación” y los descriptores específicos fueron "discapacidad" y "niños, niñas, menores de edad”. Esta búsqueda se realizó año por año, se revisaron en total 40 sentencias que cumplen con los criterios antes referidos y que se relacionan con el derecho a la educación de los niños, niñas y jóvenes en situación de discapacidad. Se resalta que la línea jurisprudencial de la Corte Constitucional, ha privilegiado una concepción especializada del derecho a la educación, se refleja las tensiones que existen en torno a la educación inclusiva, se analiza el papel del lenguaje como elemento importante de transformación social y la importancia de determinar cómo se va a llevar a cabo el proceso de implementación del derecho a la educación inclusiva. Se concluye que la presentación de la línea jurisprudencial sobre la educación, evidencia que la inclusión en el sistema general educativo es un proceso de construcción, en el cual deben participar todos los actores involucrados en su implementación y ejecución para hacerla realidad. Si 
se parte de una justificación social, de carácter humanista, que defiende la idea de que, si todos los niños y niñas aprenden juntos en escuelas inclusivas, cambiarán las actitudes frente a la diferencia y ello dará lugar a una sociedad más justa y no discriminatoria, en la que no tengan cabida los procesos de exclusión.

En Chile, Lissi y colaboradores (2009), al igual que Zuzulich y colaboradores (2014) reconocen que en los últimos veinte años se ha producido un aumento de estudiantes universitarios con discapacidad y particularmente en Chile se han observado avances en esta materia, a partir de la promulgación en 2010 de la Ley 20422 sobre igualdad de oportunidades e inclusión social de las Personas con discapacidad. El contar con una política a nivel nacional hace una diferencia importante en la asignación de recursos y en la orientación de las acciones que las instituciones deben desarrollar; sugieren que para avanzar en la inclusión y en la equidad las universidades deben tener políticas, estrategias, procesos y programas que puedan materializar dichas metas.

Castignani y colaboradores (2014) resaltan como experiencia para el avance de la inclusión en Argentina, la creación de la Comisión Universitaria sobre Discapacidad de la Universidad Nacional de la Plata, gestada con el fin de lograr la plena inclusión en el sistema universitario. Se muestran sus acciones más relevantes, su experiencia de gestión, sus objetivos y ejes de trabajo, así como las acciones que se encuentran en proceso de implementación. El trabajo de la comisión responde a la demanda frente a los procesos de inclusión que se fue afianzando a partir del año 2005, a partir de la promulgación de la Ley Nacional de Educación (Ley 26.206) que desarrolla las políticas correspondientes para garantizar trayectorias educativas integrales de los/as alumnos/as con discapacidad.

\subsection{Redes, observatorios e instancias orientadoras}

Un segundo tópico para el abordaje analítico de los antecedentes tiene relación con la Creación de Redes, Observatorios e Instancias que ofrecen orientaciones para direccionar las acciones educativas incluyentes en las IES en los países Iberoamericanos.

En México, la Asociación Nacional de Universidades e Instituciones de Educación Superior- (ANUIES) y la Secretaría de Educación Pública de México (SEP) (2004) presenta un conjunto de etapas, estrategias y acciones básicas para orientar a las instituciones que inician el proceso hacia la accesibilidad de la diversidad y se exponen recomendaciones y opciones a seguir según las condiciones de las Instituciones Educativas. Se destaca el objetivo del documento: "guiar a los responsables de las instituciones de Educación Superior en las acciones encaminadas a incluir, con igualdad y equiparación de oportunidades a las personas con discapacidad en las instituciones de educación superior del país" (ANUIES-SEP, 2004, p. 10). Se plantean los lineamientos a seguir por las universidades para la eliminación de las barreras físicas, culturales y sociales; se sugiere la creación en cada institución de educación superior del Servicio de Apoyo a la Diversidad y Discapacidad organizado como comité, programa o centro, de acuerdo a sus características y necesidades propias.

En Colombia en 2005 se crea la Red Colombiana de Instituciones de Educación Superior por la Discapacidad constituida por instituciones de educación superior, organizaciones públicas gubernamentales y privadas (no gubernamentales). Actualmente bajo la denominación de Red Colombiana de Universidades por la Discapacidad participan cuarenta y dos (42) instituciones de educación superior de las distintas regiones y nodos 
del país. La red tiene como propósito trabajar colaborativamente, aportar conocimientos y experiencias que contribuyan al proceso de inclusión de las personas con discapacidad a las instituciones de educación superior. Sobre esta base propende por el cumplimiento del derecho a la educación superior en la perspectiva de potenciar el desarrollo a escala humana por medio de asesorías técnicas, investigación y gestión social.

El estudio comparado efectuado por el Instituto Internacional de la UNESCO para la Educación Superior en América Latina y el Caribe (IESALC) presenta "un documento de referencia para quienes están interesados en los diagnósticos, tendencias y tensiones evidentes en la Educación Superior Latinoamericana y Caribeña" (UNESCO-IESALC, 2007, p. 9). El informe en su capítulo correspondiente al apartado: "Diversidad e inclusión", muestra un apartado relativo a: Integración/inclusión de las personas con Discapacidad en la Educación Superior; este documento se presenta como resultado del estudio regional "Integración de personas con discapacidad en la educación superior en América Latina y el Caribe” desarrollado por la IESALC.

Se exponen los avances tanto legislativos como de las políticas públicas que sustentan la inclusión de personas con Discapacidad con una visión Internacional y Regional en 16 países; en segundo lugar, retoma los aspectos históricos sobre la inclusión en la Educación superior y resalta las experiencias universitarias más relevantes en América del Norte y Europa y sus repercusiones en la Región de América Latina y el Caribe; un tercer apartado muestra las iniciativas gubernamentales e institucionales más relevantes a favor de la inclusión en Educación Superior en nueve (9) países de la región Latinoamericana y del Caribe; un cuarto aspecto pone el énfasis en las Fuentes de datos y estadísticas sobre las personas con discapacidad en quince (15) países de la región. Se resalta que la información sobre Colombia solo se hace evidente para el apartado tres sobre iniciativas gubernamentales e institucionales más relevantes a favor de la inclusión en Educación Superior.

Como resultado de este informe se retoma la necesidad de constituir una "Red Latinoamericana y del Caribe de Educación Superior para la Inclusión y la Diversidad", como espacio para el intercambio de experiencias y conocimientos, realización de investigaciones y para el desarrollo de propuestas y planes de acción conjuntos para la inclusión de personas con discapacidad en la educación superior que había sido mencionada en las conclusiones del "Seminario Regional sobre la inclusión de las personas con discapacidad en la Educación Superior en América Latina y el Caribe", realizado en Venezuela en diciembre de 2005 por IESALC-UNESCO.

En Mar del Plata, Argentina se crea en septiembre de 1994 la Comisión Provisoria Interuniversitaria de Discapacidad, que nucleó algunas Universidades Públicas del país. En el año 2007 obtiene su pleno reconocimiento ante el Consejo Interuniversitario Nacional a través del Programa Integral de Accesibilidad en las Universidades Públicas (Resolución 426/07). La comisión contaba en 2015 con la participación de 30 universidades públicas, y en 2017 cuenta con la participación de más de 40 universidades. La comisión se ha constituido como actor social de las Políticas Públicas de Educación Superior con miras a garantizar el cumplimiento de los derechos de las personas con discapacidad; impulsar la construcción de un espacio político; generar estrategias que permitan el cumplimiento de los derechos de las personas en situación de discapacidad; y contribuir a la conformación de Universidades accesibles y no 
excluyentes proyectando las Políticas Nacionales en articulación con el Ministerio de Educación de Argentina.

En España, Samaniego (2009), presenta los resultados de un estudio realizado por encargo del Ministerio de Educación, Política Social y Deporte de España, la Fundación ONCE para la Solidaridad con Personas Ciegas de América Latina y el Comité Español de Representantes de Personas con Discapacidad, para disponer de una línea base sobre aspectos relacionados con la situación actual del acceso a servicios educativos de las personas con discapacidad en Latinoamérica. Toda vez que ha entrado en vigor la Convención de Naciones Unidas sobre los derechos de las personas con discapacidad, este estudio constituye una primera aproximación desde la normatividad y la conceptualización, desde la perspectiva de los informes internacionales y recoge el pronunciamiento oficial de las instancias de Educación Especial de los Ministerios de Educación, la percepción de diversos actores como personas con discapacidad, familiares, profesionales y sociedad en general, así como la vivencia institucional en los países de América Latina y del Caribe: Argentina, Bolivia, Brasil, Chile, Colombia, Costa Rica, Cuba, Ecuador, El Salvador, Guatemala, Honduras, México, Nicaragua, Panamá, Paraguay, Perú, República Dominicana, Uruguay y Venezuela.

En Chile, Lissi y colaboradores (2009) plantean un modelo que da cuenta de las condiciones que deben estar presentes para que pueda constituirse en un entorno inclusivo. Se busca compartir la experiencia del Programa para la Inclusión de Estudiantes con Necesidades Especiales, adelantado en la Universidad Católica de Chile, con dos años de funcionamiento para generar condiciones de equidad para los estudiantes con discapacidad física, sensorial o motora y contribuir al desarrollo de iniciativas efectivas que permitan entornos cada vez más inclusivos en los contextos universitarios Chilenos.

La Red Interuniversitaria Latinoamericana y del Caribe sobre Discapacidad y Derechos Humanos fue constituida formalmente en abril de 2009, acogiendo las recomendaciones de la UNESCO-IESALC (2007). Es un espacio de encuentro, reflexión, debate e intercambio de experiencias y posiciones teóricas con el fin de construir conocimientos y generar las políticas institucionales necesarias para propiciar condiciones de equidad en la vida universitaria. Está integrada por instituciones de Educación Superior, cátedras, grupos de investigación, de extensión y personas vinculadas a la discapacidad en las universidades. Participan representantes de 17 países de la región: de Argentina, Bolivia, Brasil, Chile, Costa Rica, Colombia, Cuba, Ecuador, Guatemala, México, Nicaragua, Panamá, Paraguay, Puerto Rico, República Dominicana, Uruguay y Venezuela.

En junio de 2012 con la promoción del SENADIS para la creación de las Redes regionales de IES Inclusivas (públicas y privadas) en todo el país, se constituye la Red nacional de educación superior inclusiva en Chile. Su objetivo es el intercambio de conocimientos, información y experiencias en torno a la promoción de la inclusión educacional y social de las personas en situación de discapacidad e impulsar políticas públicas para garantizar los derechos de estos estudiantes. El acta constitutiva de la red concibe la educación inclusiva como "un conjunto de procesos, tanto individuales como colectivos, que se instalan al interior de las instituciones de educación con la finalidad de promocionar el desarrollo de todos y todas las personas, en una cultura de respeto y reconocimiento de la dignidad intrínseca y de los derechos iguales e inalienables de todos los miembros de la familia humana”. Es un concepto amplio, con una mirada intercultural que beneficia no 
sólo a los estudiantes, sino que también a los académicos, funcionarios y administrativos, un concepto que se enmarca en una cultura de derechos humanos.

Otro antecedente importante orientado a la consolidación de acciones conjuntas en red, es el de Pérez, Fernández y Katz (2013), quienes presentan un documento conjunto de la Red interuniversitaria latinoamericana y del caribe sobre discapacidad y derechos humanos. Esta Red fue constituida formalmente en abril de 2009; se reúnen en Buenos Aires, los miembros de la Comisión interuniversitaria de discapacidad y derechos humanos de la Argentina, que nuclea a las Universidades Públicas del país (alrededor de 40 Universidades Públicas Nacionales), la representante de la Red Colombiana de Universidades por la Discapacidad y representantes de Universidades de Panamá, Brasil, Chile, Uruguay y México. En síntesis, se logró contar con representantes de más de cincuenta universidades de la región, quienes dan surgimiento a la Red a través del Manifiesto de Buenos Aires, definiéndose los siguientes objetivos orientadores:

- Afirmar los derechos de las personas con discapacidad, promoviendo conciencia en los ámbitos académicos y de diseño y gestión de políticas de educación superior, de la necesidad de erradicar definitivamente de la vida universitaria, el prejuicio y la discriminación;

- Hacer de todo espacio educativo un entorno no excluyente a través de acciones que permitan la accesibilidad física, comunicacional, académica y cultural de todas las personas;

- Incorporar al currículo de las disciplinas universitarias y asignaturas, contenidos formativos referidos a la discapacidad desde la perspectiva de los derechos humanos;

- Crear las condiciones para la producción académica en la temática de la discapacidad en docencia, investigación y extensión a fin de propiciar conocimientos y prácticas respetuosas de los derechos humanos y de condiciones de vida dignas, dando cumplimiento a lo estipulado por la Convención sobre los derechos de las personas con discapacidad de la Organización de las Naciones Unidas;

- Propiciar el intercambio de experiencias y recursos que pudiesen fortalecer las políticas vinculadas a la docencia, extensión e investigación en la temática de la discapacidad;

- Promover cartas de intención y/o convenios con organismos públicos nacionales e internacionales y organizaciones de la sociedad civil a nivel nacional e internacional, con el fin de garantizar los derechos de las personas con discapacidad;

- Favorecer la creación en las instituciones de educación superior de una instancia que cuente con los recursos para desarrollar acciones efectivas y sostenidas que respondan a las necesidades de las personas con discapacidad en dichas instituciones;

- Difundir e implementar por todos los medios al alcance de esta Red la convención internacional sobre derechos de las personas con discapacidad y el Plan de acción de la OEA sobre dignidad y derechos de esta población. 
La red propone acciones para su avance reconociendo los esfuerzos de las Universidades Latinoamericanas en pro de los derechos humanos de la personas con discapacidad; promueve la divulgación de los avances en temas como la accesibilidad, los apoyos pedagógicos y tecnológicos disponibles; propicia el intercambio, difusión y transferencia de experiencias a nivel académico de extensión, docencia e investigación que contribuyen a la promoción de los derechos de las personas discapacitadas, a la formación profesional y al compromiso universitario en la temática y promueve la incorporación de nuevas instituciones de educación superior al trabajo de la red. Se considera que la red puede jugar un rol importante para promover, afirmar y difundir los derechos de las personas con discapacidad, generar e intercambiar conocimientos que posibiliten una mayor inclusión en la educación superior y apoyar el desarrollo de políticas de educación superior en la región orientadas a eliminar la discriminación y barreras que enfrentan las PcD.

En Argentina, Castignani y colaboradores (2014) muestran la experiencia de gestión, sus objetivos y ejes de trabajo, así como las acciones que se encuentran en proceso de implementación de la Comisión Universitaria sobre Discapacidad de la Universidad Nacional de la Plata, creada desde 1999 con el fin de lograr la plena inclusión en el sistema universitario, que todos puedan ingresar y transitar la universidad para estudiar, trabajar y participar de las diversas propuestas que la misma genera. El trabajo de la comisión organiza líneas de trabajo permanentes a partir de los siguientes propósitos: a) promover la inclusión expresa de la misión enunciada en el Estatuto de la Universidad Nacional de la Plata; b) propiciar en el ámbito de cada facultad acciones tendientes a favorecer la inclusión, evitando y eliminando las barreras físicas, de acceso a la información, académicas y actitudinales que puedan obstaculizarla, c) promover dentro del ámbito académico la incorporación de la temática de la discapacidad en todo currículo de carreras de pre-grado, grado y post-grado; d) encomendar el desarrollo de proyectos universitarios de docencia, investigación y extensión que incluyan la temática de la discapacidad; e) coordinar la programación de encuentros interuniversitarios; f) establecer intercambio de información y/o acciones de cooperación con entidades, redes y organismos municipales, provinciales, nacionales e internacionales.

En el Perú, Bregaglio (2014) señala que los centros de formación superior juegan un rol fundamental en la protección de las personas con discapacidad a través de un cambio estructural del modelo educativo, que se adhiere al modelo de inclusión cuya fundamentación es el modelo social. No obstante, lograr la plena inclusión de las personas con discapacidad implica la superación de una serie de barreras en materia de acceso y permanencia; el informe busca identificar dichas barreras, así como las buenas prácticas de superación de las mismas, en la Pontificia Universidad Católica del Perú. El objetivo planteado es identificar los estándares que debe cumplir toda institución de educación superior en esta materia con respecto a todos los miembros de la comunidad académica: docentes, estudiantes y trabajadores. La autora considera que el documento sirve como una hoja de ruta para la mejora de los mecanismos de acceso y permanencia de estudiantes con discapacidad en la Pontificia Universidad Católica del Perú y en otras instituciones de educación superior en el Perú.

En España se ha configurado el Observatorio Universidad y Discapacidad que tiene la misión de estudiar y analizar lo relativo a la discapacidad, la accesibilidad universal, el diseño para todos y la educación inclusiva en las universidades españolas. El Observatorio Universidad y Discapacidad fue creado en 2008 por la Fundación ONCE 
(2014) para la cooperación e integración social de las personas con discapacidad. Se destaca que este proyecto planteado de una forma universal e inclusiva, conduce a su implementación técnica, al compromiso político, a la colaboración efectiva entre las distintas universidades y al mantenimiento sostenido en el tiempo del sistema. Los beneficios serán muchos y se posibilitará un mayor conocimiento de la situación real de la comunidad universitaria en cuanto a: la discapacidad (problemas, necesidades, satisfacción); promoción y generación de conocimiento científico sobre la materia al proveer a los investigadores de datos reales, veraces y actuales; toma de decisiones por parte de la dirección de las universidades basadas en datos estadísticos fiables sobre su accesibilidad; creación de políticas y estrategias efectivas a nivel estatal gracias a la disponibilidad de información global; posibilidad asociativa de datos para llevar a cabo evaluaciones de estado en sus respectivos ámbitos; sensibilización de la sociedad y del sector empresarial sobre la igualdad de oportunidades; información y sensibilización a los docentes sobre la diversidad y ofrecimiento a los estudiantes con discapacidad de información sobre su realidad en la universidad.

Un antecedente importante en relación con la creación de Instancias del orden institucional es el propuesto por Garzón y Molina (2014) en Colombia, resultante de la investigación "Propuesta metodológica para la construcción de una política universitaria de inclusión y convivencia de estudiantes con discapacidad en educación superior", financiada por los fondos de Extensión e Investigación de la Universidad del Rosario. El interés particular de este proceso de documentación fue generar la posibilidad de marcar un tránsito de la idea de servicio de apoyo, con que fue creado IncluSer en el año 2008, hacia una orientación que abogue por el sentido de la participación y reconocimiento de los estudiantes con discapacidad al interior de la Universidad, con el propósito de promover la disposición institucional a la reflexión, el diálogo y la construcción colectiva de realidades institucionales posibles para los estudiantes con discapacidad y a la comunidad universitaria en general, en términos de acceso, innovación, flexibilidad curricular, formación integral, entre otros. Igualmente se buscó ampliar los espacios de visibilización institucional, con el fin de permear canales de comunicación orientados a la agencia y construcción de una comunidad académica que se comprometa con los fines que IncluSer tiene proyectados. Se establece la proyección institucional de las líneas de acción en relación con la participación de estudiantes con discapacidad en la Universidad del Rosario a través de:

- La estructuración de un programa transversal a todas las unidades académicas de la Universidad como respuesta a una política institucional de inclusión y convivencia de estudiantes con discapacidad en educación superior;

- La conformación de un equipo de trabajo focalizado de carácter interdisciplinario con dependencia a unidades que promuevan la agencia institucional de procesos pedagógicos, tecnológicos, de infraestructura y bienestar;

- Procesos de información y formación a profesores y funcionarios, a través de la articulación con diferentes unidades de la misma Universidad o referentes externos;

- Soporte pedagógico, tecnológico y de accesibilidad (señalización, movilidad y comunicación); 
- Cumplimiento con estándares de calidad y lineamientos de acreditación nacional e internacional relacionados con la perspectiva de inclusión y convivencia de personas con discapacidad en educación superior;

- Hacer parte de redes nacionales e internacionales en el campo de la educación superior inclusiva;

- La agencia y promoción de investigación, extensión en el campo, como centro de gestión de conocimiento;

- Las capacidades de IncluSer se verían potenciadas en la medida que su programa y sus acciones estén orientadas desde la concepción misional de la Universidad, para que entren en diálogo y en articulación formal con otras dependencias, que guardan relación con la vida académica de un estudiante, desde el proceso de información institucional, el proceso de admisiones, de seguimiento tutorial, de bienestar y convivencia, de concepción y gestión curricular, procesos de aprendizaje, beneficios académicos y económicos y de seguimiento como egresados.

En noviembre de 2015 en México se crea la Red de Estudiantes Latinoamericanos por la Inclusión. Su objetivo es desarrollar propuestas para fortalecer los procesos de inclusión en los establecimientos educativos; su objetivo es generar condiciones de accesibilidad, permanencia e igualdad de oportunidades para todos los estudiantes, cuyo valor central es el reconocimiento de la diversidad como valor social. Tiene como misión ser un referente internacional en la creación, sistematización y discusión de buenas prácticas de inclusión para personas en situación de Discapacidad (redrelpi.wixsite.com)

\subsection{Acciones adelantadas y avances}

Una tercera categoría de análisis resultante de la revisión de antecedente es la referente a las acciones adelantadas por las IES y sus avances.

Rodríguez (2004) en el Ecuador resalta que las personas con discapacidad y sus familias han conformado organizaciones y federaciones, cuyo objetivo fundamental es velar por la promoción y cumplimiento de los derechos de las personas con discapacidad; a la vez resalta la red de organizaciones privadas que trabajan ofertando diferentes servicios alas $\mathrm{PcD}$. Estas redes de organizaciones de y para personas con discapacidad, han facilitado en gran medida la atención y participación social de las mismas.

En España, Samaniego (2009), analiza los escenarios nacionales y el regionales en los países de América Latina y del Caribe: Argentina, Bolivia, Brasil, Chile, Colombia, Costa Rica, Cuba, Ecuador, El Salvador, Guatemala, Honduras, México, Nicaragua, Panamá, Paraguay, Perú, República Dominicana, Uruguay y Venezuela. Examina el rol decisivo de los organismos públicos, privados, cooperantes y de la sociedad civil que incluye buena parte del capital humano de un país; se aportan propuestas y se plantean estrategias para la expansión de los servicios y la optimización de recursos, tanto propios como aquellos provenientes de la cooperación.

Espinosa, Gómez y Cañedo (2012) en el Ecuador proponen un modelo para la gestión del proceso de acceso y retención de estudiantes universitarios con discapacidad, desde un enfoque pedagógico, a partir de un estudio sobre la problemática de la inclusión en una muestra de universidades de la provincia del Guayas. Se propone un Plan de Formación Docente con soportes para la implementación de las etapas del modelo 
propuesto y se definen los indicadores para la evaluación del mismo. Afirman que las estrategias desarrolladas para garantizar el acceso y retención de estudiantes con discapacidad en las IES se centra solo en ofrecer tratamientos especiales en el orden financiero para dichos estudiantes. (becas, ayudas económicas y aranceles diferenciados). El modelo que se propone está encaminado no solo a fortalecer y profesionalizar, sino que pretende también preparar, en el llamado Programa de Carrera Docente, a los profesores y estudiantes, quienes se transformarán en los futuros docentes universitarios, que garantizarán la contextualización práctica del pleno acceso y el tratamiento a la diversidad al interior de las Instituciones de Educación Superior.

En Chile, Lissi y colaboradores (2009) señalan como avances que, los programas revisados en la Universidad Católica de Chile cuentan con apoyo institucional, muchos de ellos incorporan a distintos actores en las acciones adelantadas, cuentan con políticas de apoyo para el ingreso y para la permanencia (becas, apoyos metodológicos, apoyo a profesores).

Castignani y colaboradores (2014), destacan como ejes del trabajo adelantado por la comisión universitaria sobre discapacidad en Argentina las siguientes actividades: capacitación docente; relaciones interinstitucionales (participación en la Comisión interuniversitaria de discapacidad y derechos Humanos de Argentina y en la Red interuniversitaria latinoamericana y del Caribe sobre discapacidad y derechos humanos); asesoramiento e intercambio con organismos del gobierno y organizaciones no gubernamentales vinculadas a la temática de la discapacidad.

Giraldo (2013) reconoce que a pesar de las múltiples dificultades, existe en Colombia un avance importante en torno a la construcción del proceso de educación inclusiva: el planteamiento de una política pública nacional, un conjunto de la normativas que la soportan y los fundamentos jurisprudenciales trazados por la Corte Constitucional que orientan las prácticas inclusivas desarrolladas por los entes territoriales e institucionales.

Garzón y Molina (2014) identifican las acciones y avances de IncluSer de la Universidad del Rosario (Colombia) en relación a su infraestructura física y tecnológica, incorporación de sistemas de registro con el departamento de admisiones; actividades de gestión, apoyo académico e investigación, actividades de diseminación y visibilización. Los desarrollos institucionales logrados a partir de este que se observan especialmente en la autonomía tanto académica como social de los estudiantes con discapacidad y en las relaciones intra e interpersonales con la comunidad académica que han favorecido la participación en la vida universitaria.

Bregaglio (2014) plantea que, en el marco del mandato de no discriminación, de la Pontificia Universidad Católica del Perú, la Oficina Central de Admisión e Informes ha tomado diversas medidas orientadas a garantizar la realización de estos ajustes en el proceso de admisión; cabe resaltar el problema de las personas con discapacidad intelectual y psicosocial para las cuales no se tiene ningún protocolo de atención. En el caso de la discapacidad psicosocial, podría ocurrir que muchos postulantes no hayan acreditado su discapacidad, lo que impediría que sean beneficiarios de las becas o bonificaciones. El otorgamiento de estas becas se hace a través de la oficina de apoyo social cuando detecta un caso que lo requiera (en el caso de discapacidad, se requiere certificado de CONADIS). 
En cuanto a las adaptaciones metodológicas se vienen dando de manera espontánea, de acuerdo a la intuición de cada profesor; en particular, las facultades avisan a los profesores y jefes de práctica que van a tener a estudiantes con discapacidad la primera semana de clases, buscando que estos puedan realizar ajustes en su manera de dictar sus clases. Los docentes coinciden en la necesidad de contar con un protocolo metodológico para la inclusión que asegure que el estudiante con discapacidad tenga las mismas oportunidades y reciba la misma educación que un estudiante sin discapacidad. En relación a la adaptación de evaluaciones, los estudiantes con discapacidad visual pueden realizar sus evaluaciones en otro espacio distinto al salón asignado para todo el resto de alumnos, para que pue dan contar con un lector o puedan utilizar la computadora. También se permite que los estudiantes con discapacidad física puedan usar un salón de la primera planta o que el estudiante con discapacidad física pueda contar con más tiempo para escribir. En el caso de los estudiantes con baja visión, también se ha logrado que puedan contar con impresiones ampliadas. Facilidades en matrícula: se permite que los estudiantes con discapacidad tengan preferencia al momento de realizar la matrícula y que puedan armar su horario combinándolo adecuadamente con las terapias que puedan requerir, haciendo más sencillo su traslado hacia la universidad.

La Fundación ONCE (2014) en España reconoce como avances en la implementación de políticas de inclusión, las siguientes: la Universidad Politécnica de Cataluña se hace cargo del pago de los intérpretes de lengua de señas, cuenta con un servicio de digitalización de textos, se trabaja con varias cátedras en las carreras de Diseño, Arquitectura, Periodismo y Comunicación, Educación Física, Trabajo Social, Informática, Psicología, en la transversalización de contenidos vinculados a la discapacidad, entre otros. Igualmente, el Observatorio Universidad y Discapacidad ha apoyado la creación de la Cátedra de Accesibilidad de la Universidad Politécnica de Cataluña. La cátedra tiene como finalidad facilitar el acceso de a las $\mathrm{PcD}$, de forma autónoma, a cualquier entorno, sea arquitectónico, tecnológico o de conocimiento. La Cátedra concentra sus esfuerzos en tres líneas de actuación: la adecuación tecnológica y su uso, la eliminación de barreras y la mejora del acceso a la información y el conocimiento (infoaccesibilidad). Señala que los trabajos realizados por el Observatorio Universidad y Discapacidad, aportan las reflexiones necesarias para trabajar en la consecución de un sistema de información que permita analizar aspectos como las características y requerimientos de las personas con discapacidad, los servicios que la universidad les ofrece, el estado de la accesibilidad universal (en edificios, instalaciones, servicios, cursos o actividades formativas, actividades no formativas, etc.); la situación de la incorporación de los conceptos y criterios del diseño para todos o las actividades de información o sensibilización relacionadas con la accesibilidad universal; recopilar los datos estadísticos para extraer el conocimiento sobre la evolución del sistema universitario español y las especificaciones necesarias para su implementación.

Teniendo como marco de trabajo la Ley de Protección de Datos Personales, el análisis establece que los datos de salud del alumnado son los más sensibles en su compartición y gestión. La premisa legal de disociar los datos vinculados a la identidad del alumnado con discapacidad del resto, se ha resuelto mediante un protocolo de agregación anónima de datos que garantiza estrictamente el cumplimiento de la ley (Fundación ONCE, 2014).

\subsection{Restricciones y obstáculos}


Un cuarto eje del análisis efectuado tiene relación con las restricciones y obstáculos que se evidencian en los procesos de inclusión en la educación superior. Al respecto, Rodríguez (2004) en el Ecuador, señala las múltiples restricciones de tipo económico, social, técnico y político que dificultan el acceso, la permanencia y el egreso de la población a este nivel educativo. No existe un proyecto común que regule y coordine los esfuerzos de las instituciones de educación superior que han empezado su implementación, "lo cual contrasta con un marco legal que explícitamente señala las obligaciones de instituciones y organismos, a fin de propiciar la integración de estas personas al Sistema de Educación Superior" (Rodríguez, 2004, p. 16).

El Consejo Nacional de Educación superior, no tiene un Registro Oficial, ni bases de datos, que identifiquen a las IES que hayan implementado programas y sistemas de apoyo para facilitar el acceso y permanencia de las personas con discapacidad. Existen pocas bases de datos oficiales que registren las características de edad, sexo, procedencia, nivel de instrucción, empleo, condición socioeconómica, etc. de la población con discapacidad y no se registra información oficial sobre: formación y capacitación, programas de sensibilización a la comunidad universitaria, eliminación de barreras arquitectónicas, urbanísticas y de accesibilidad al transporte, adaptaciones tecnológicas, adaptaciones curriculares.

Sverdilick, Ferrari y Jaimovich (2005) establecen que "una cuestión preocupante en relación con las políticas afirmativas es la ausencia de datos acerca de sus beneficiarios, así como también de seguimientos que permitan valorar la incidencia que estas políticas tienen en la democratización de los sistemas" (p. 21). Se trata de políticas afirmativas destinadas a indígenas y sectores minoritarios (entre ellos las personas con discapacidad) que se aplican sin datos oficiales acerca de las condiciones de acceso, retención y egreso de este sector en los diferentes niveles de enseñanza, particularmente en la educación superior. En este sentido, no se trata de políticas integrales que redunden en un beneficio hacia los grupos sociales más pobres o minoritarios, sino que se encuentran enfocadas a moderar las diferencias existentes entre aquellos que efectivamente logran llegar hasta la universidad. En aquellos casos nacionales en los que coexisten políticas afirmativas con exámenes de ingreso y cupos para la educación superior, podría argumentarse que las políticas afirmativas se dirigen en un sentido contrario a los sistemas de ingreso. Esto es, políticas que incorporan condiciones especiales para minorías específicas en los exámenes de ingreso (como serían las políticas para el caso de Colombia) que refuerzan, más que cuestionan, el carácter meritocrático del examen de ingreso y estigmatizan a quienes se benefician de ellas; de esta manera, muchas de estas políticas resultan insuficientes para modificar las relaciones entre los grupos sociales, tanto en lo que se refiere a la sociedad en general como a la composición social de la educación superior en particular.

Aponte (2008), demuestra que a pesar del aumento en la demanda y la oferta de las oportunidades de estudio (acceso), se observa una diferenciación de alcance de cobertura, un aumento de los costos de los estudios y heterogeneidad en los niveles de calidad de las instituciones de educación superior, generándose más exclusión que inclusión. Se analiza la falta de efectividad de las políticas de inclusión en la región, lo cual puede tener un gran impacto al aumentar la desigualdad existente, profundizar la brecha cognitiva, de conocimiento y digital, impulsando la migración y fuga de talentos, elevando el desempleo y generando un impacto negativo en la cohesión y el tejido social. 
Pedroza y Villalobos (2009), ofrecen una panorámica del problema de la inequidad en la educación superior en Ecuador y Perú. Particularmente en relación con la población con discapacidad los autores señalan que esto se debe a que existen importantes restricciones que dificultan el acceso, permanencia y egreso de la población con discapacidad. En Perú, no se dispone de cifras exactas de las personas con discapacidad y específicamente sobre educación de personas con discapacidad; no se encuentran datos que permitan establecer el resultado de dichas iniciativas; son notorios los rezagos en el desarrollo e implementación de políticas, lo que ha impedido que los beneficios de este tipo de educación lleguen a toda la población, existiendo jóvenes que aún no son atendidos en este nivel educativo.

Samaniego (2009), concluye en su estudio comparado que en los países Latinoamericanos no se tienen datos certeros sobre niñez, adolescencia y juventud con discapacidad, pues no se llega a considerar su inclusión en el sistema educativo como un indicador de gestión; un segmento grande de ellos no es atendido y es invisibilizado sin posibilitar una acción con responsabilidad social. La retención de las personas con discapacidad en el sistema educativo recae en su mayoría en los docentes; sin embargo, no se dispone aún de los recursos necesarios para dar cumplimiento a lo previsto en las normativas. El profesor de aula tiene una formación de base insuficiente y hay escasas ofertas de capacitación sobre la temática. Teóricamente se remite "el caso" a un equipo multidisciplinario que no siempre existe en las instituciones o se recurre a las instancias ministeriales que al no contar con el personal suficiente impele a la búsqueda de profesionales externos de apoyo cuyos honorarios no suelen estar al alcance de las familias. Los sistemas educativos en nueve países latinoamericanos signatarios del Convenio Andrés Bello evidencian la evaluación escolar con fines promocionales más que una evaluación formativa, entrelazada con edades mínimas de ingreso a los diferentes niveles lo que propicia una rigidez a la que debe adaptarse el estudiante con discapacidad. No se encuentra información sobre la participación activa de estudiantes con discapacidad en la vida escolar y fuera de ella, excepto en el caso de Colombia donde se ha recabado información basada en evidencia en la educación básica a través de la herramienta "Indicadores de buenas prácticas de educación inclusiva" (Ministerio de Educación Nacional, 2004). Es importante notar que varios países informan sobre la incorporación de componentes que encaminan la educación hacia una práctica inclusiva, aunque la cobertura no sea total ni se cuente aún con los recursos indispensables cabe resaltar el esfuerzo y el impulso que se requiere para continuar.

Lissi y colaboradores (2009) confirman fallas en la implementación de las políticas existentes que dejan de manifiesto que el tema de la discapacidad siga siendo ignorado y se encuentra ausente como problemática en el debate de la Educación Superior Chilena. Castignani y colaboradores (2014), identifican que los mayores obstáculos que enfrenta una persona con discapacidad para acceder, permanecer y egresar de la educación superior en Argentina están relacionados con la percepción social de la discapacidad y las barreras actitudinales; por otro lado, aún existen obstáculos desde lo arquitectónico y urbanístico, de transporte, de comunicación y acceso a la información; dificultades para el acompañamiento pedagógico; dificultades para acceder a la bibliografía digitalizada y a las TIC's que facilitan la labor cotidiana del estudiante, como lectores de pantalla, sintetizadores de voz, transcripción electrónica de contenidos, teclados virtuales.

Moreno (2010) afirma que aún existe una brecha importante entre las aspiraciones contempladas por la legislación Colombiana y la realidad que viven las personas con 
discapacidad; con base en las limitaciones identificadas y aunque la normatividad colombiana ha registrado avances hacia constituirse en una política en discapacidad para la población infantil, no logra abarcar las profundas consecuencias que se derivan del mandato de justicia y vida digna a que tienen derecho los niños, niñas y jóvenes colombianos con discapacidad y sus familias. Una de las causas de la brecha entre legislación y realidad tiene que ver con fallas en la implementación de la normatividad, en tanto los destinatarios de los programas y servicios no logran acceder a ellos, aun cuando son titulares de estos derechos. Sin embargo, no todos los problemas son atribuibles a fallas en la implementación de las normas, también se hacen evidentes las deficiencias relacionadas, con la concepción que sustenta la normatividad colombiana sobre lo que debería entenderse como "justicia para las personas con discapacidad". De acuerdo con las conclusiones del estudio exploratorio, la normatividad colombiana para niños y jóvenes con discapacidad presenta restricciones y debilidades manifiestas en los conceptos nucleares subyacentes a la política en discapacidad, reflejan restricciones de los principios constitucionales como la vida, la libertad y la igualdad, los cuales conforman un sistema coherente con los principios éticos (dignidad, familia como fundamento y vida en comunidad) y principios administrativos (capacidad instalada de profesionales y del sistema, individualización y rendición de cuentas). Este sistema articula, una teoría sobre política en discapacidad (Turnbull y Stowe, 2001, citados por Moreno, 2010), la cual, sin duda, intersecta con el terreno disciplinario de la teoría de la justicia. Esta situación, sugiere la existencia de lo que se denomina un estado de cosas inconstitucionales. Esta figura jurídica se refiere a:

\begin{abstract}
situaciones de vulneración de los derechos fundamentales que tienen un carácter general, en tanto que afectan a multitud de personas y cuyas causas son de naturaleza estructural, esto es, que generalmente la causa de la vulneración no se origina, de manera exclusiva, en la autoridad demandada y, por tanto, su solución exige la acción mancomunada de distintas entidades. (Tole, 2006, p. 7, citado por Moreno, 2010)
\end{abstract}

El estudio de Moreno (2010) mostró que la normatividad colombiana en discapacidad privilegia, distorsiona, restringe y excluye los conceptos que fundamentan los instrumentos jurídicos que pretenden garantizar la vida digna a los niños, niñas y jóvenes colombianos con discapacidad y sus familias. En las concepciones que se identifican en sus diferentes documentos, la normatividad colombiana para niños y jóvenes con discapacidad no expresa de manera suficiente los principios básicos para la garantía de los derechos constitucionales, tales como la libertad, la vida digna y la igualdad, interpretada desde los argumentos de la teoría de la justicia propuestos por Rawls, Sen y Nussbaum retomados por Moreno (2010). Esta insuficiencia se aprecia en el debilitamiento de cinco planteamientos, articulados entre sí, e indicadores de los derechos constitucionales: 1) el principio de la libertad y 2) el principio de la diferencia de Rawls; 3) la noción de funcionamientos; 4) la noción de capacidades de Sen; y 5) la noción de vida digna de Nussbaum.

Espinosa, Gómez y Cañedo (2012) plantean que en el Ecuador la inclusión en la educación superior no se materializa en acciones concretas y medibles. Las acciones propias de las instituciones educativas se sustentan en general en el esfuerzo individual de cada docente en cuanto a los contenidos académicos, las alternativas didácticas y el nivel de especialización; se requiere de un conjunto de estrategias específicas, bien pensadas y diseñadas, para lograr una actuación sistémica en tal sentido. 
Bregaglio (2014) en su estudio de la Pontificia Universidad Católica del Perú (PUCP), presenta como resultado del diagnóstico sobre la inclusión de personas con discapacidad en la PUCP, la ausencia de datos ciertos y uniformes respecto a la realidad de las personas con discapacidad en la PUCP. A nivel interno, la PUCP no cuenta con un registro propio de estudiantes, docentes o trabajadores con discapacidad. De manera referencial, se puede señalar que desde el semestre 2005-1 al 2013-2 se ha registrado el ingreso de 31 estudiantes con discapacidad. No obstante, debe tenerse en cuenta que este registro tiene dos limitaciones i) solo toma en alumnos admitidos por ingreso regular (lo cual excluye otras modalidades como ingreso) y solo consigna a aquellos alumnos que se declararon y acreditaron como personas con discapacidad, por lo que seguramente existirá una cifra de discapacidad oculta y no se incluye a los estudiantes que adquieren la discapacidad luego del ingreso. Asimismo, los participantes de la comunidad PUCP en sus tres tipos (alumnos, docentes y administrativos), muestran actitudes más positivas hacia las personas con discapacidad física; quedan por debajo los otros tipos de discapacidades, siendo la discapacidad sensorial la que menos actitudes favorables presenta. En relación a la accesibilidad se evidencia que la mayor cantidad de edificios de facultades cuentan con acceso adecuado en sus primeros pisos, es decir, que la PUCP es accesible para estudiantes con discapacidad física. No obstante, cuando se midió la accesibilidad vertical, es decir, hacia los pisos superiores, se constató que, de los 21 edificios, solo cinco cuentan con un ascensor o rampa que permita ascender a pisos superiores por un medio diferente a la escalera. Sólo el ascensor de un edificio es accesible para personas con discapacidad visual (teclas en braille y audio que informen el piso en el que se encuentra). Nueve edificios de facultad no cuentan con al menos un baño adaptado para el uso de personas en sillas de ruedas en el primer piso y de los 12 edificios que sí cuentan con el baño adaptado, ocho presentan un ancho de puerta de ingreso al cuarto de baño y/o al cubículo adaptado es menor a 0,90, por lo cual una silla de ruedas no puede ingresar. En el caso de los baños de los 21 edificios supervisados, si bien la mayoría (16 de ellos) presentan lavatorios con espacios libres, solo los baños de un edificio cumplen con la altura de $85 \mathrm{~cm}$. En relación con los ajustes razonables en el examen de ingreso, no existe un documento de gestión que ordene la realización de estos.

\subsection{Recomendaciones y prospectiva}

La quinta categoría analítica identificada en los documentos analizados, corresponde a las recomendaciones y prospectiva o visión de futuro para la Educación superior inclusiva.

ANUIES-SEP (2004) sugiere la creación en cada institución de educación superior del Servicio de Apoyo a la Diversidad y Discapacidad (SADID) como un comité, programa o centro, de acuerdo a sus características y necesidades propias, este organismo podrá promover las acciones que puedan considerar fundamentales a partir de las etapas y estrategias propuestas en el manual: a) organización, que contempla la constitución de la comisión interdisciplinaria y del SADID, b) el establecimiento de red interna institucional, c) establecimiento de redes de vinculación externa; d) sistematización: incluye la documentación de experiencias de inclusión y su análisis e) evaluación y seguimiento: a partir de la definición de los indicadores de evaluación, evaluación de las acciones, el análisis de los resultados y el ajuste del programa.

Rodríguez (2004) en Ecuador señala como recomendaciones a) aprovechar el marco legal y político existente en materia de discapacidades e implementar planes de acción que 
comprometan, regulen y coordinen los esfuerzos de todas las IES, en pos de la integración educativa de las personas con discapacidad; b) unificar términos y tipologías utilizadas por las instituciones educativas para atender, integrar y planificar programas educativos para las personas con discapacidad; c) procesar y sistematizar información sobre las características específicas de la población con discapacidad; d) generar información oficial sobre las características de las instituciones de educación superior, en relación a la formación y capacitación los programas de sensibilización a la comunidad universitaria, la eliminación de barreras arquitectónicas, urbanísticas y de accesibilidad al transporte, las adaptaciones tecnológicas y las adaptaciones curriculares; e) fortalecer técnica y económicamente el Proyecto "Universidad para todos".

UNESCO-IESALC (2007) insta a las instituciones de educación superior a dictar normas afirmativas, diseñar y desarrollar programas permanentes y compromisos a favor de la Inclusión; se exhorta igualmente a los gobiernos e instancias de Acreditación de la Educación Superior a tomar medidas en favor de las personas con discapacidad para su inclusión en los estudios superiores.

Aponte (2008) propone líneas de acción orientadas a atender los cambios en el perfil social del estudiantado:

como resultado de la creciente masificación de la educación superior: feminización,
estudiantes como clientes, estudiantes de corto tiempo, estudiantes profesionales,
estudiantes trabajadores, estudiantes a distancia, estudiantes indígenas, estudiantes
con diversidad racial, estudiantes con discapacidades, junto a los ya tradicionales
estudiantes, se hace necesario adelantar programas para atender las
particularidades derivadas de esta diferenciación social, en pos de una mayor
equidad. (p. 268)

Samaniego (2009) afirma que es necesario que los movimientos asociativos de personas con discapacidad y sus familias abran espacios que consoliden su posicionamiento social. Señala líneas de acción relacionadas con formación inicial docente con componentes sobre NEE, capacitación en funciones, dotación de ayudas técnicas y material didáctico adaptado, incorporación de equipos multidisciplinarios y personal docente de apoyo, servicios para la detección de discapacidades y orientación vocacional; así como para el acompañamiento y asesoramiento a docentes, eliminación o al menos disminución de barreras al medio físico y a la comunicación, flexibilización del curriculum e impulso al liderazgo institucional y a la innovación curricular, procesos de sensibilización y concienciación, apertura a la participación de la familia, iniciativas para garantizar la continuidad de estudios y facilitar la inserción laboral.

Se finaliza el análisis planteando que la batalla contra la marginalidad y la exclusión podrá ser ganada en la medida en que se fortalezcan la calidad de las condiciones, procesos e insumos. Promover el acceso, garantizar aprendizajes efectivos, obtener al menos una educación básica equitativa y propender a un nivel superior, implica la eliminación de las barreras al medio físico, a la comunicación e información, así como la supresión de barreras psicológicas y estructurales (en lo político, institucional, pedagógico, curricular y docente). Asumir la educación como un bien público, generar una interdependencia entre calidad, equidad e igualdad de oportunidades, es responsabilidad insustituible de los gobiernos y compromiso de la sociedad. Considera que todo aquello que se plantea desde la perspectiva de la discapacidad coadyuva al mejoramiento de la sociedad en su conjunto; en consecuencia, los sistemas de apoyo que se plantean para eliminar las barreras al aprendizaje y responder a las necesidades 
educativas especiales asociadas a la discapacidad abren un horizonte más amplio que respeta la individualidad y garantiza a la población el acceso a los aprendizajes.

Lissi y colaboradores (2009) afirman que, aunque en Chile aún no es posible hablar de universidad inclusiva, se puede afirmar que está en vías de serlo y que cada día se detectan nuevas demandas que ayudan a regular acciones y procedimientos que finalmente se traducen en políticas a favor de la inclusión en las IES. Plantean que el éxito de las iniciativas para la inclusión en la IES se facilitará en la medida en que se hagan mayores avances en la implementación de una educación más inclusiva. El ideal es identificar líneas de acción comunes a las IES, tales como: a) realizar sensibilización, difusión y capacitación a los miembros de la comunidad universitaria que ayuden a superar las barreras para la inclusión, b) gestionar recursos para la adecuación de infraestructura, c) estructurar una oferta extracurricular que garantice el acceso de los estudiantes discapacitados, d) disponer de recursos tecnológicos específicos de acuerdo con el tipo de discapacidad, e) crear mecanismos de adecuación curricular de acuerdo con las limitaciones físicas de los estudiantes, f) implementar un programa de egreso de la universidad e ingreso a la vida laboral, g) contar con un equipo específico de investigación en el tema que pueda evaluar los impactos de los programas en las tasas de egreso y h) Contar con bases de datos o censos respecto al ingreso y egreso de este tipo de estudiantes. Finalmente sugieren la creación de redes e intercambio de experiencias entre las distintas universidades, con el fin de lograr espacios inclusivos.

Crosso (2010), como recomendaciones destaca que los Estados que han firmado la Convención sobre los Derechos de las Personas con Discapacidad, están obligados a sensibilizar a la sociedad, incluso a nivel familiar, para que tome mayor conciencia respecto de las personas con discapacidad y fomentar el respeto de los derechos y la dignidad de estas personas promoviendo el reconocimiento de las capacidades, los méritos y las habilidades de las personas con discapacidad y sus aportaciones.

Otra recomendación clave es garantizar una comprensión profunda del sentido de educación inclusiva presente en los marcos normativos internacionales para que, más allá de la existencia de una legislación y unas políticas nacionales que la impulsen, ocurran cambios concretos en la práctica escolar, en sus contenidos y abordajes, como también en la manera como se desarrollan las relaciones en el interior del aula. Ratificar el conjunto de normativas que impulsan el derecho a la educación de personas con discapacidad es otro paso clave y urgente que tiene que ocurrir, como es el caso de la Convención interamericana sobre discapacidad y la convención sobre los derechos de las personas con discapacidad de la ONU. Se deberá procurar la participación de la comunidad, incluida la de los propios alumnos/as con discapacidad, en la toma de decisiones sobre la política y la legislación, por medio del fomento de la capacidad, la lucha contra hábitos y actitudes discriminatorias y las ideas equivocadas sobre las personas con discapacidad. Urge que los Ministerios de Educación dispongan de datos confiables sobre el número de estudiantes con discapacidad atendidos en los diversos niveles y modalidades educativas, tanto en términos de acceso como en términos de su permanencia y conclusión.

Si bien la política de educación de algunos Estados observa el concepto de educación inclusiva y las medidas y obligaciones contenidas en los instrumentos internacionales, el financiamiento inadecuado afecta su implementación, repercutiendo negativamente en las garantías para la efectiva inclusión educativa: salarios adecuados y capacitación 
inicial y en servicio de docentes y de personal conexo, recursos y profesionales de apoyo suficientes, adaptaciones curriculares y metodológicas, infraestructura y mobiliario accesible, materiales educativos adaptados, entre otros. Estos profesionales deben estar habilitados para la enseñanza del lenguaje de señas y Braille, con profunda conciencia sobre las distintas deficiencias, y estar preparados para el uso de medios y formatos de comunicación aumentativa y alternativa, así como de técnicas y materiales pedagógicos de apoyo para las personas con discapacidad. Es por eso que los esfuerzos hacia la realización del derecho a la educación de personas con discapacidad deben venir acompañados de esfuerzos por consolidar sistemas públicos de educación calificados, que brinden el derecho a la educación de todos y todas.

Espinosa, Gómez y Cañedo (2012) consideran que la instrumentación del modelo para la gestión del proceso de acceso y retención de estudiantes universitarios con discapacidad supone la conformación de un equipo cuya función principal se centra en la organización, coordinación del programa y medición de los impactos de los resultados del mismo así como la presencia de expertos en la profesionalización de docentes universitarios en Pedagogía, Didáctica general, Didácticas específicas y Gestión universitaria quienes impartirán los módulos temáticos, los talleres y quienes realizarán el acompañamiento necesario en el proceso de investigación, formarán equipos de investigación-acción para el estudio de los principales problemas existentes en el contexto educativo ecuatoriano y formularán propuestas y asesorías para la mitigación de las insuficiencias plasmadas en los diagnósticos realizados. El modelo elaborado y su implementación permitirá lograr el reto de trabajar por la educación para todos.

Giraldo (2013) argumenta que en Colombia, se evidencia la necesidad de fortalecer el papel de cada uno de los actores señalados, dado que si bien existe una política pública acerca de la importancia de implementar la educación inclusiva con un amplio desarrollo legislativo, su materialización presenta grandes dificultades como la exigencia de los padres por una educación especializada y la renuencia a la inclusión de sus hijos, debido a su temor frente a la exclusión y burlas de las que ellos puedan ser víctimas; y por esta vía y la falta de sensibilización de la comunidad educativa en general frente a la realidad de la discapacidad. La educación inclusiva es un proceso de construcción por parte de todos los actores involucrados en su materialización efectiva, como también por toda la sociedad, la cual debe transformar el imaginario y los lenguajes acerca del concepto de discapacidad para asumirla como inherente a una realidad que siempre ha existido y como una posibilidad para transformar la sociedad.

Zuzulich y colaboradores (2014) concluyen que, si la misión del Mineduc es asegurar un sistema educativo equitativo y de calidad que contribuya a la formación integral y permanente de las personas y al desarrollo del país, esta misión invita a abordar el tema de la inclusión, focalizándose en que los estudiantes con discapacidad, al igual que todos, puedan aprender en condiciones de calidad y equidad. Acceder y permanecer en la universidad constituye un desafío importante para los estudiantes con discapacidad, sus profesores y las instituciones; y si ese desafío se aborda a nivel país los resultados pueden ser mejores en términos de aumentar la participación y disminuir la discriminación. Además, ofrece la posibilidad de reflexionar, sobre la forma en que una universidad más inclusiva puede aportar a la sociedad en momentos en que en Chile se discuten los elementos para una reforma educacional y se plantea este desafío de avanzar hacia universidades más inclusivas. 
Bregaglio (2014) en su estudio de la Pontificia Universidad Católica del Perú explicita las necesidades de los docentes, quienes señalan la importancia de una mayor capacitación por parte del instituto para la docencia universitaria, ente encargado de la formación metodológica de los profesores de la universidad. Cabe resaltar, que la universidad cuenta con la experiencia del diplomado en educación inclusiva y atención a la diversidad de la facultad de educación por lo cual sería posible trasladar dicha experiencia a todo el ámbito universitario que permita las adaptaciones curriculares y metodológicas que exige la educación inclusiva. El documento formula recomendaciones para emprender la tarea que le corresponde a la universidad como actor social fundamental en la construcción de una sociedad más justa para las personas con discapacidad. Con relación a: a) acceso, b) permanencia al interior del campus y de cada unidad académica, c) ajustes razonables laborales para docentes y trabajadores con Discapacidad, c) promover iniciativas de responsabilidad social que apunten a la eliminación de las diferentes barreras d) Sensibilización y Capacitación.

\section{Conclusiones}

$\mathrm{Al}$ efectuar un análisis frente a este conjunto de antecedentes Internacionales y Nacionales que dan cuenta de los lineamientos, las políticas públicas y lineamientos institucionales para el acceso a la educación superior de la población con discapacidad es posible afirmar que si bien, existe un vasto soporte constitucional y legal en la mayoría de los países iberoamericanos, sobre los derechos de las personas con discapacidad, no es claro aún en qué forma operan estos marcos normativos en los múltiples y diversos procesos y tipos de escolarización de la Educación superior ni cómo se regula su tránsito en la Educación superior en los diversos niveles: técnica, tecnológica, profesional y postgradual; si bien, son amplias las descripciones de los obstáculos, limitaciones, dificultades y tensiones observadas en la implementación de los lineamientos de Inclusión, no son claros los análisis evaluativos en las IES que den cuenta de la implementación cotidiana de los procesos educativos y pedagógicos inmersos en la Inclusión Educativa, de los múltiples aspectos y recursos que garantizan la calidad y equidad educativa para las personas con discapacidad, ni de las condiciones que dinamizan y potencializan las prácticas incluyentes en la educación superior.

En los países Latinoamericanos aún se evidencian fallas en la implementación de unos sistemas públicos de calidad que atiendan a la población en cuestión y que afectan sus derechos básicos, pues esconden detrás el gran paradigma de la marginación y la pobreza. En esta panorámica, se observa la posición de -último lugar- de las prioridades y posibilidades a la satisfacción de las necesidades educativas de la población con discapacidad. Factores como la pobreza, la edad (primera infancia o ancianidad) el género y la opción sexual u otras condiciones de exclusión, las condiciones y dinámicas de las familias y sus condiciones socio-económicas y culturales, las oportunidades de inserción laboral, etc., son factores que promueven adicionalmente dobles o múltiples formas de exclusión de las personas con discapacidad; sin embargo, aunque estas son reconocidas pues se constatan en las declaraciones de los organismos internaciones-, no ha sido posible aún superarlos o erradicarlas y siguen hoy vigentes. Los sistemas educativos precarios, no calificados y de baja calidad no promueven la superación de la exclusión; igualmente, la privatización y tercerización de la Educación Superior y los recortes en el 
sistema público educativo en la región son otros factores que ensombrecen el futuro de la educación de calidad, los cuales deben ser analizados.

Se destaca en los países de Iberoamérica el papel de las Organizaciones No Gubernamentales y organizaciones de la sociedad civil en la dinamización y promoción de las políticas públicas; ellas han jugado papel muy destacado, especialmente las asociaciones de personas con discapacidad y sus familias. Un buen número de ONG'S, que en conjunto trabajan en este campo, han ayudado a develar las realidades y necesidades de la población con discapacidad y han estado dispuestas a atender a una población que ha sido dejada a la deriva y a suplir las carencias que los gobiernos no atienden.

Hoy día es común hablar de inclusión en los ámbitos normativos, gubernamentales, no gubernamentales y académicos; pero en las prácticas todavía hay mucho trecho que recorrer. Los sistemas educativos en sus distintos niveles tienen aún serias dificultades para alcanzar la inclusión en forma efectiva obteniendo los objetivos que se propone en términos de desarrollo humano para todos los sectores sociales tradicionalmente excluidos, entre ellos a la población con discapacidad.

El caso concreto de la atención educativa de las personas con discapacidad, todavía hoy se visibiliza como un campo débil y vulnerable. Aun así, se han incorporado progresivamente diversos componentes, inicialmente en la Educación Básica y en los últimos años en la Educación Superior, que encaminan la educación hacia una práctica inclusiva, aunque su cobertura no sea total, ni se cuente aún con los recursos indispensables y necesarios para dar cumplimiento a lo previsto en las normativas por parte de los actores y de los beneficiarios; el deficiente ejercicio de la ciudadanía por parte de las propias personas con discapacidad contribuye a la reproducción de las dinámicas excluyentes y al incumplimiento por parte del Estado de su función planificadora y reguladora que repercute en los diversos sectores sociales.

Se resalta que la construcción de lineamientos de política para la atención educativa de la población con discapacidad en las instituciones de educación superior en Iberoamérica es relativamente reciente; pero la implementación de esas políticas de Inclusión en las IES, no es fácil ni transparente y no siempre se tiene un correlato tangible en las prácticas educativas. A pesar de ello, se evidencia que hay esfuerzos encaminados hacia la inclusión de las personas con discapacidad en la Educación Superior, se resalta el esfuerzo y el impulso que se requiere para dar inicio al proceso en los últimos diez años, considerando que es bastante difícil lograr una participación mayor de los jóvenes con discapacidad en la Educación Superior al no garantizarse el acceso y la permanencia en los niveles previos, cuyo carácter progresivo funciona como filtro que paulatinamente impide el ingreso al siguiente nivel. La progresiva disminución de población estudiantil con discapacidad al pasar de un nivel a otro se maximiza en la educación superior que se muestra como el nivel más excluyente de todos.

Se han generado importantes iniciativas en las IES que al mantenerse y ampliarse no solo garantizan el acceso y permanencia, la participación y el aprendizaje, sino que redundan en un incremento de profesionales con discapacidad competentes para incorporarse e incluirse al mundo, social y cultural que aportarán al desarrollo y progreso de sus localidades, de sus países y por supuesto de la región latinoamericana; pero, son incipientes los análisis evaluativos sobre las estrategias de implementación, adecuación, adaptación y adopción de las políticas públicas de inclusión a la educación superior de las personas con discapacidad en las instituciones. 
Tomando en cuenta que las instituciones de educación superior en la región son en su mayoría de carácter privado, se destaca que hay iniciativas válidas a favor de la Inclusión tanto de instituciones públicas y privadas, que se orientan especialmente a adoptar medidas para facilitar el acceso, disponer de programas y/o servicios de apoyo para la permanencia e incorporar la temática en los proyectos de desarrollo institucional, de investigación y de proyección social. Con estas iniciativas y sus avances, se ha trazado un camino que debe continuarse y donde, existe al menos la sensación de que se han logrado situar o concretar las palabras presentes en los discursos y que se está intentando dar el salto de la "teoría" sobre la Inclusión a las "prácticas" de Educación Inclusiva e incluyente. Se observa el incremento de la educación virtual y a distancia como una alternativa importante para la inclusión en la educación superior.

Como obstáculos para el ingreso y la permanencia de los estudiantes con discapacidad en la educación superior se destacan: la insuficiencia de las políticas gubernamentales macro ante la falta de voluntad y decisión para su implementación en las diversas Instituciones e instancias universitarias; el desconocimiento sobre la temática por parte de los docentes que al no tener una formación de BASE generan barreras al aprendizaje, las barreras psicológicas y éticas (ignorancia y prejuicios) que se manifiestan en actitudes negativas hacia la Inclusión; otros obstáculos tienen relación con eliminación de las barreras físicas y arquitectónicas, las barreras de la comunicación e información, barreras estructurales (en lo político, institucional, pedagógico, curricular y docente), y las barreras socio-culturales. Se reconoce que aunque las TIC se constituyen una herramienta efectiva para la inclusión educativa, no alcanzan la cobertura requerida y la mayoría de la población con discapacidad no tiene acceso aún a ellas. Finalmente, los estudios muestran, especialmente en América Latina una baja caracterización de los aspectos sociodemográficos de la población de jóvenes con discapacidad, sus condiciones de acceso, permanencia y egreso de la educación superior.

Se destaca como fortaleza la constitución y avances en las acciones implementadas en las redes de Instituciones y estudiantes que se interesan por la progresiva consolidación de una Educación superior inclusiva, tanto en los ámbitos nacionales como a nivel latinoamericano, las cuales han posibilitado espacios de participación, investigación, intercambio y divulgación de saberes y prácticas de inclusión de cada país, para continuar contribuyendo a la inclusión de las personas con discapacidad en la educación superior.

\section{Referencias}

Aponte, H. E. (2008). Desigualdad, inclusión y equidad en la educación superior en América Latina y el Caribe: tendencias y escenario alternativo en el horizonte 2021. En A. Gazzola y A. Didriksson (Eds.), Tendencias de la educación superior en América Latina y el Caribe.(pp. 79-98). Caracas: IESAC-UNESCO.

ANUIES-SEP. (2004). Manual para la integración de personas con discapacidad en las instituciones de educación superior. Ciudad de México: Secretaría de Educación Pública.

Bregaglio, L. R. (2014). Hacia una universidad para todos: propuesta para una PUCP inclusiva. Lima: Pontificia Universidad Católica del Perú. 
Castignani, M., Hanlon, P., Luján, M., Katz, S. y Peiró, M. (2014). Comisión universitaria sobre Discapacidad: Una experiencia de gestión en la Universidad Nacional de La Plata. Revista Latinoamericana de Educación Inclusiva, 8(1), 51-61.

Crosso, C. (2010). El derecho a la educación de personas con discapacidad: Impulsando el concepto de educación inclusiva. Revista Latinoamericana de Educación Inclusiva, 4(2), 79-95.

Espinosa, C., Gómez, V. y Cañedo, C. (2012). ¿Integración o inclusión? La educación superior ecuatoriana y el pleno acceso de estudiantes con discapacidad. Revista Ciencia y Sociedad, 37 (3), 1-19.

Flórez, R., Moreno, M., Bermúdez, J. y Cuevo, C (2009). Lineamientos de política para la atención educativa de las poblaciones en situación de discapacidad en las instituciones de educación superior en Colombia. Revista Areté. Fonoaudiología Iberoamericana, 9, 358-376.

Fundación ONCE. (2014). Definición de un sistema global de información en materia de discapacidad en la universidad. Barcelona: Universidad Politécnica de Cataluña.

Garzón, D. K. y Molina, B. K. (2014). IncluSer. Del apoyo, a la participación y reconocimiento de estudiantes con discapacidad en la Universidad del Rosario. Bogotá: Editorial Universidad del Rosario.

Giraldo, G. V. (2013). El derecho a la educación de los niños, niñas y jóvenes en situación de discapacidad. Una sistematización jurisprudencial de los fallos de la Corte Constitucional Colombiana (1992-2011) (Tesis de maestría). Universidad Nacional de Colombia.

Lissi, M. R., Zuzulich, M. S., Salinas, M., Hojas, A. M., Achiardi, C. y Pedrals, N. (2009). Inclusión y Discapacidad en Contextos Universitarios: La experiencia del PIANE-UC. Revista Calidad en la Educación, 30, 306-323.

Moreno A. M. (2010). Infancia, políticas y discapacidad (Tesis doctoral). Bogotá: Universidad Nacional de Colombia.

ONU (2008). Conferencia internacional de educación. La educación inclusiva: un camino hacia el futuro. Recuperado de: http://www.ibe.unesco.org/

Organización Mundial de la Salud. (2011). Informe mundial sobre discapacidad. Malta: World Health.

Pedroza, F. F. y Villalobos M. G. (2009). Políticas compensatorias para la equidad en la educación superior en Ecuador y Perú. Buenos Aires: Centro Argentino de Estudios Internacionales.

Pérez, L., Fernández, A. y Katz, S. (2013). Discapacidad en Latinoamérica. Voces y experiencias universitarias. Buenos Aires: Editorial de la Universidad de la Plata EDULP.

Rodríguez, N. (2004). Integración de las personas con discapacidad en la educación superior en Ecuador. Recuperado de http://unesdoc.unesco.org/images/0014/001404/140488s.pdf

Samaniego, P. (2009). Personas con discapacidad y acceso a servicios educativos en Latinoamérica. Breve Análisis de situación. Madrid: Grupo Editorial CINCA.

Sverdilick, I., Ferrari, P. y Jaimovich, A. (2005). Desigualdad e inclusión en la educación superior. Un estudio comparado en cinco países de América Latina. Brasilia: OLPED-SEPPIR.

UNESCO-IESALC. (2007). Informe sobre la educación superior en América Latina y el Caribe 20002005. La metamorfosis de la educación superior. Buenos Aires: UNESCO

Zuzulich, M. S., Achiardi, C., Hojas, A. M. y Lissi, M. R. (2014). Inclusión de Estudiantes con discapacidad en universidades chilenas: mecanismos de admisión y recursos para su implementación. Recuperado de http://politicaspublicas.uc.cl/ 


\section{Breve CV de la autora}

\section{Myriam Stella Fajardo Becerra}

Fonoaudióloga. Especialista en Aprendizaje Escolar y sus Dificultades. Magíster en Desarrollo Educativo y Social. Candidata al Doctorado en Ciencias Sociales, Niñez y Juventud (Universidad de Manizales-CINDE). Docente e investigadora de pregrado y postgrado en programas de Educación y Fonoaudiología. Experta en la dirección, asesoría y evaluación de proyectos de investigación con énfasis en los campos del lenguaje, comunicación-educación, aprendizaje escolar, dificultades del aprendizaje e inclusión educativa. Docente de apoyo a la inclusión de la Secretaría de Educación Distrital de Bogotá con competencias en la atención de Necesidades Educativas Especiales, en la formulación e implementación de proyectos de desarrollo educativo y pedagógico, proyectos para la promoción de los aprendizajes escolares e inclusión educativa. ORCID ID: 0000-0002-1894-2173. Email: mystelafabe9699@gmail.com 